\section{Assessment of lateral groundwater flows in the SJV}

\author{
Mark E. Grismer $\square$ R. Craig Woodring
}

\section{Relatively small, but potentially significant}

$\mathbf{K}_{\mathrm{n}}$ nowledge of subsurface lateral flow of shallow groundwater is important in efficient management of irrigation and drainage water in the western San Joaquin Valley. Physical and economic models necessary to develop management strategies require information on the volume of subsurface flows. The purpose of this study was to assess and quantify the direction and magnitude of subsurface lateral flows in a roughly 100 -square-mile region, based on data currently available from public water agencies.

\section{Data collection}

Information was compiled in cooperation with the California Department of Water Resources, U.S. Department of Agriculture Soil Conservation Service, U.S. Bureau of Reclamation, U.S. Geological Survey, and Westlands Water District. Primary data on lateral flows included geologic surveys, drillers' logs, and water table elevations. Considerable effort was required to find the appropriate data, if any, and to organize it into a cohesive and consistent system.

In collecting and organizing the data, it became apparent that information on key physical properties of the soils needed to determine lateral flows was essentially nonexistent. Moreover, water level figures were limited for much of the valley. Regions containing the greatest number of data points were in the Westlands Water District and data collection efforts on subsurface water flows were therefore concentrated in this area.

Collected information was organized by township and range covering approximately 40 townships along the west side of the San Joaquin Valley. Major sources of information used in this study are summarized by storage location and type in table 1. Additional sources contained in various reports are also available. (Presently, all collected information is contained in notebooks and computer files in Veihmeyer Hall at the University of California, Davis.)

\section{Soil profile hydraulic features}

Because of major deficiencies in collected data on quantification of soil hydraulic properties, we estimated hydraulic conductivities of soil profiles from soil textures identified in drillers' logs (table 2). Soil profile conductivity was taken as the weighted average of all textural layers to a depth of 30 to 50 feet, at which a dense clay layer was generally located. Transmissivity was calculated as the product of profile conductivity and depth to dense clay. No information was found describing differing transmission characteristics of individual layers within the soil profile, so estimated values of hydraulic conductivity assume uniform properties. Such an assumption is consistent with the level of accuracy involved in estimation of hydraulic conductivity.

\section{Subsurface lateral flows}

The complexity of the area involved and the scarcity of data made it impossible to quantify magnitude and directions of lateral subsurface flows at the township scale. Hydraulic transmissivity values developed from available data averaged less than one per square mile. Water level observations averaged roughly four per square mile. Because of this relatively meager amount of data from the most densely sampled area in the San Joaquin Valley, estimates of lateral subsurface flow represent gross regional values. They cannot be applied to smaller scales since local geologic differences, such as buried alluvial channels, soil texture, and structural discontinuities, will dominate both flow directions and magnitudes.

Regional estimates of subsurface lateral flows required calculations of transmissivity and water table levels between points of estimated or measured values. Contour maps of calculated and measured values were generated using a fortran computer program that triangulates irregularly spaced data and determines appropriate values for a user-selectable grid. Estimates of partial figures resulting from calculated values were based on five adjacent data points, because this yielded the clearest contour maps.

There were 187 values of soil hydraulic conductivity estimated in the study region with an average of 6 feet per day. The range in hydraulic conductivities was typical of analyses at the regional scale. In addition, further analysis indicated that individual values of hydraulic conductivity were independent, or not related

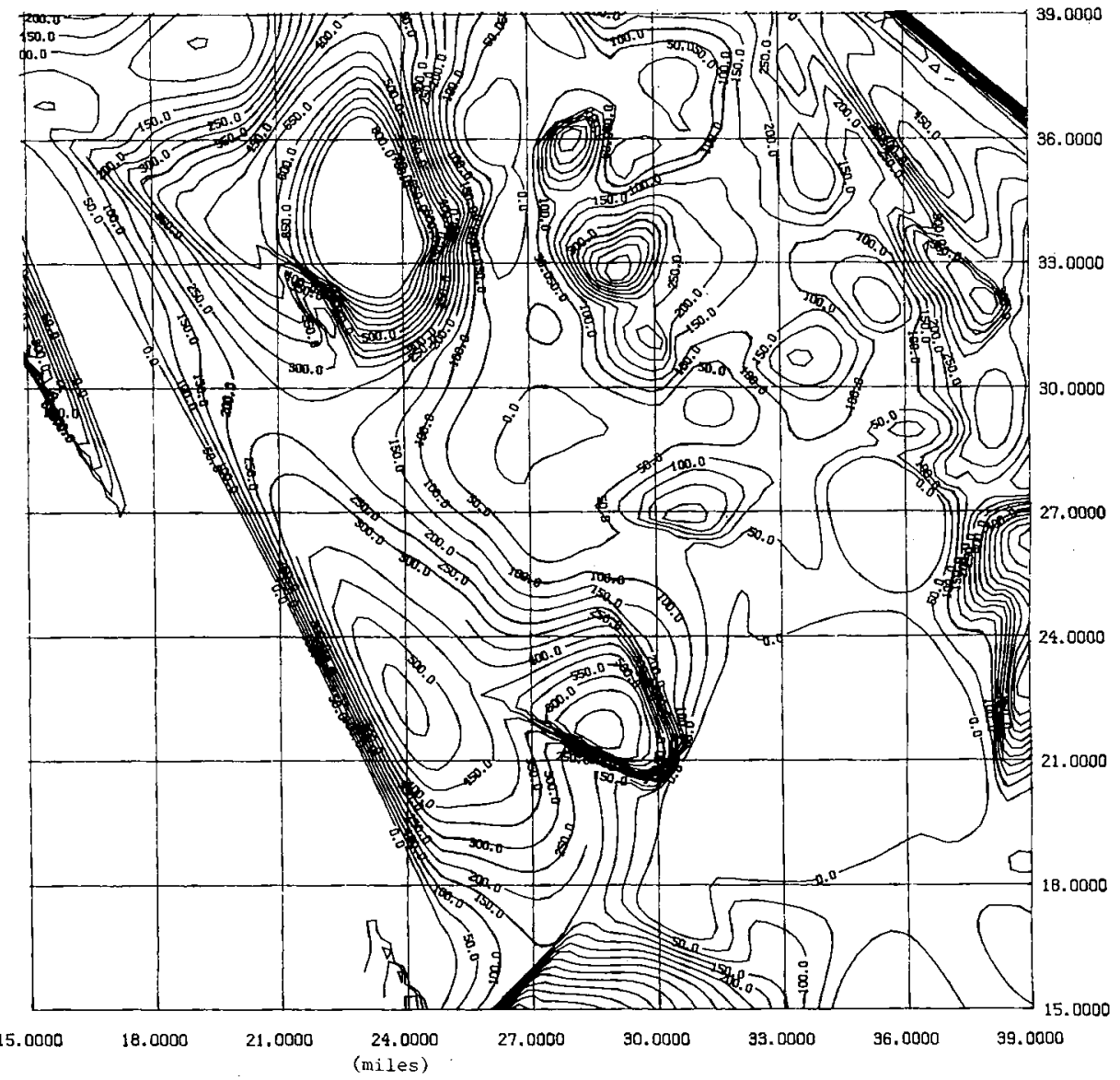

Fig. 1. Portion of a contour map of the study region showing transmissivity in square feet per day. 
TABLE 1. Major sources of hydrologic data related to subsurface lateral flows in the San Joaquin Valley (SJV)

\begin{tabular}{|c|c|}
\hline Storage location & Description of data \\
\hline $\begin{array}{l}\text { Department of Water Resources, } \\
\text { SJV District Office }\end{array}$ & $\begin{array}{l}\text { - estimates of specific yield } \\
\text { - soil profile logs (20-ft depth) } \\
\text { from } 1958 \text { - } 1962 \text { survey } \\
\text { - water well driliers' logs } \\
\text { - land use maps }\end{array}$ \\
\hline $\begin{array}{l}\text { U.S. Bureau of Reclamation, } \\
\text { Sacramento Office } \\
\text { (also Westlands Water District) }\end{array}$ & $\begin{array}{l}\text { - quarterly groundwater levels for } \\
\text { approximately } 500 \text { shallow } \\
(<25 \mathrm{ft} \text { deep) wells } \\
\text { - San Luis drain observation } \\
\text { well water levels }\end{array}$ \\
\hline $\begin{array}{l}\text { U.S. Geological Survey, } \\
\text { Sacramento Office }\end{array}$ & $\begin{array}{l}\text { - tabular review of all well data } \\
\text { from approximately } 3700 \text { wells }\end{array}$ \\
\hline
\end{tabular}

TABLE 2. Hydraulic conductivity assigned to various soil types

\begin{tabular}{lcl}
\hline Soil type & $\begin{array}{c}\text { Hydraulic } \\
\text { conductivity }\end{array}$ & \multicolumn{1}{c}{$\begin{array}{c}\text { Analogous terms on } \\
\text { drillers' logs }\end{array}$} \\
\hline Clay & $\begin{array}{c}\text { ft/day } \\
0.001\end{array}$ & - \\
Clay loam & 0.6 & $\begin{array}{l}\text { Surface soil and clay } \\
\text { Soil and clay } \\
\text { Soil and yellow clay } \\
\text { Brown clay }\end{array}$ \\
Clay sand & & $\begin{array}{l}\text { Black sand with ooze } \\
\text { Silty sand }\end{array}$ \\
Silt & 1.0 & $\begin{array}{l}\text { Sand and clay streaks } \\
\text { Silt loam }\end{array}$ \\
Fine sand & & Silt loam, loamy silt \\
Medium sand & 1.5 & Very fine sand \\
Coarse sand & 2.5 & Sand, medium grey sand \\
Gravel & 6.0 & Blue sand, black sand \\
\hline
\end{tabular}

to neighboring values. A more detailed study at the smaller township scale in the northeastern edge of Westlands Water District yielded a smaller average conductivity, characteristic of the area, but a substantially larger range in values. Such large variation at the township scale may reflect geologic differences not detected at the regional scale used here.

Figures 1 and 2 illustrate contours of transmissivity and water table elevations for a portion of the study region. From these two maps, and similar maps for the remainder of the region, qualitative estimates of volumes and directions of sub- surface lateral flows were made. Assuming horizontal uniformity of the soil profile, lateral flow direction is roughly perpendicular to contours of decreasing water table elevations. Magnitudes of lateral flows are the product of the transmissivity in the specific area and the rate of water table elevation decline with distance in the direction of flow. Minimum and maximum estimated flow rates were approximately 0.1 and 5.0 cubic feet per foot per day (4.4 and 220-acre-feet per mile per year).

Contour maps of water table elevations for April and October in selected

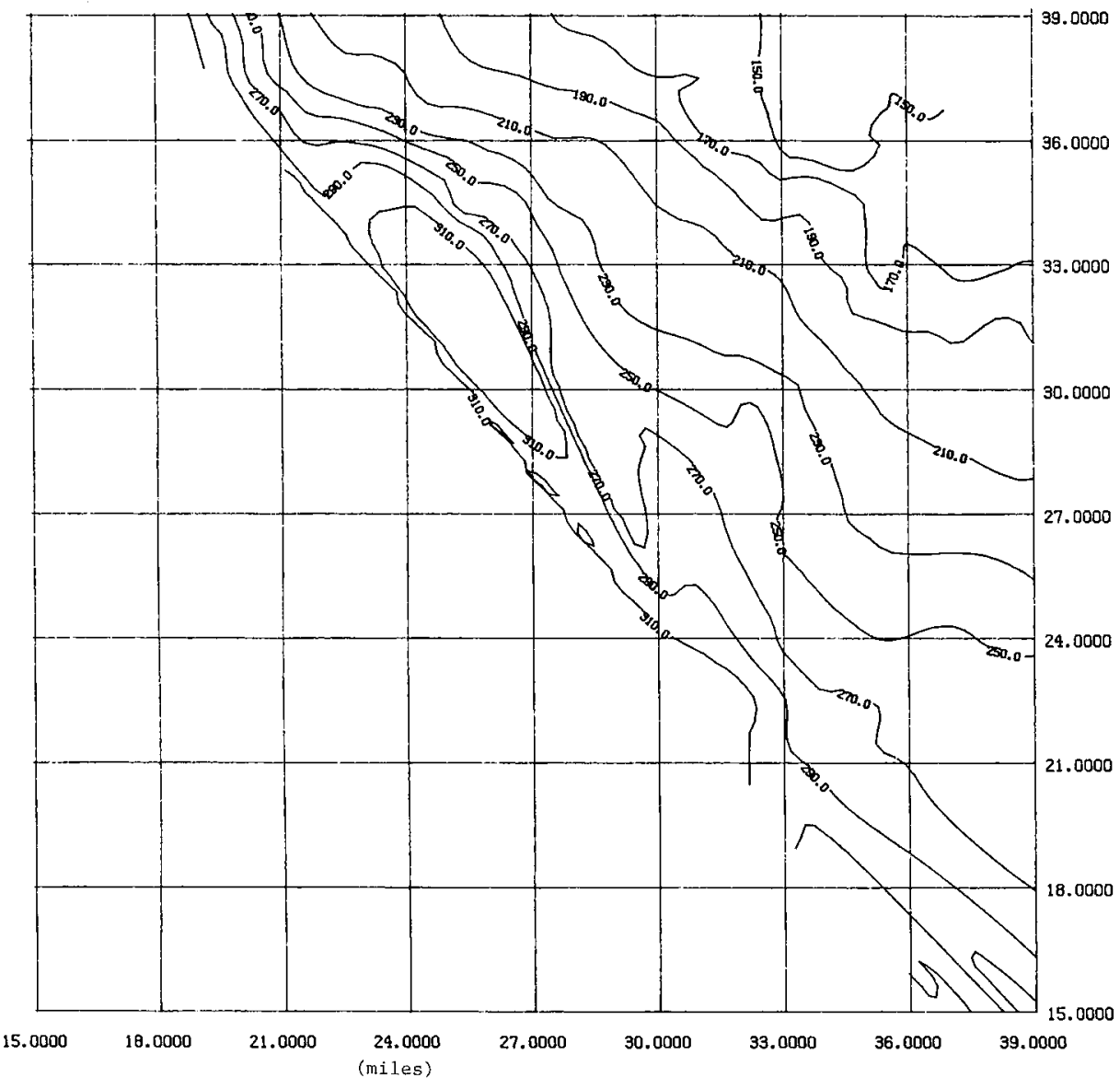

Fig. 2. Portion of study area showing water table elevation in feet above sea level. years during the past decade were also examined. Based on these maps, there appears to have been little substantial change in regional subsurface lateral flow patterns during this time.

\section{Assessment and conclusions}

Regional analysis of available data on subsurface lateral flows is complex because of the limited data and variability of hydrogeologic conditions. This study represents a first attempt at quantification of these flows using data presently available. Unfortunately, meager data for the region involved and a total lack of detailed information on hydraulic properties of soil profiles in the region prevent accurate assessment of lateral flows at smaller scales. For example, it is possible to generate contour maps like figures 1 and 2 at the township scale, but analysis of lateral flows at this scale is speculative, because the typical township contains less than 10 estimates of transmissivity and approximately 30 water table elevations. At this scale and below, local hydrogeologic conditions control directions and magnitudes of subsurface lateral flows.

Detailed regional assessment of subsurface lateral flows requires a more dense sampling, which includes accurate analyses of the hydraulic properties of the shallow aquifer. As an option, intensive studies at a smaller scale in "typical" areas within the region may be used to estimate lateral flow in the entire region. In either case, current costs of such sampling programs are very large.

From presently available data, qualitative estimates of lateral flow rates are variable, relatively small (on the order of 30 acre-feet per mile per year), and potentially significant. Their significance influences the future of agricultural production and environmental interests in the San Joaquin Valley.

Mark E. Grismer is Assistant Professor, Department of Land, Air and Water Resources (LAWR) and of Agricultural Engineering, University of California Davis; and R. Craig Woodring is former post-graduate researcher, Department of LAWR, UC Davis. 